\title{
Evaluation of Olfactory Acuity in Patients with Coronavirus Disease 2019 (COVID-19)
}

\author{
Naveed Nazir Shah ${ }^{1} \cdot$ Raj Tajamul Hussain ${ }^{2}$ (1) Hena Mustafa ${ }^{1}$ Mehvish Mushtaq ${ }^{1}$. \\ Mariya Ali ${ }^{1}$
}

Received: 20 September 2020/ Accepted: 19 October 2020/Published online: 27 October 2020

(C) Association of Otolaryngologists of India 2020

\begin{abstract}
Aim and Objectives To describe the prevalence and characteristics of olfactory dysfunction (OD) in patients with laboratory-confirmed COVID-19 infection.

Materials and Methods This monocentric study was performed at Chest Diseases Hospital during the COVID-19 pandemic and all patients testing positive for COVID-19 over a 5-month period (April to August 2020) were recruited. Detailed history was elicited from subjects and all patients were inquired about olfactory dysfunction (OD). Patients with olfactory dysfunction were asked to complete olfactory questionnaires based on the short version of the Questionnaire of Olfactory Disorders-Negative Statements (sQOD-NS).

Results 655 patients with mild to moderate COVID-19 infection were included in the study. The prevalence rate of olfactory dysfunction was $18.47 \%(n=121)$ with contribution of $11.60 \%(n=76)$ and $6.87 \%(n=45)$ from anosmia and hyposmia respectively, thereby suggesting olfactory dysfunction to be a significant clinical feature in COVID-19 patients. Males were significantly more affected by olfactory dysfunctions than females. Anosmic patients had significantly reduced sQOD-NS results as compared to hyposmic patients (significant at $P<0.05$ ). The mean duration of OD was 7.7 days $( \pm 4.3)$ and $>90 \%$ patients in our study showed resolution within 14 days.
\end{abstract}

Raj Tajamul Hussain

raj.tajamul@gmail.com

Naveed Nazir Shah

naveedazirshah@yahoo.com

Department of Respiratory Medicine, GMC, Srinagar, India

2 Department of Otorhinolaryngology, SHKMGMC, Nuh, India
Conclusion The early recognition of olfactory dysfunction should help to screen, identify and thereby quickly isolate mildly symptomatic COVID-19 patients from the general population and the existence of these dysfunctions may well be a prognostic factor in the course of the disease.

Keywords Coronavirus · COVID-19 - SARS-CoV-2 . Olfactory dysfunction · Anosmia $\cdot$ Hyposmia $\cdot$ sQOD-NS . Kashmir

\section{Introduction}

Coronavirus disease 2019 (COVID-19) is caused by a newly discovered coronavirus. The virus is now known as the severe acute respiratory syndrome coronavirus 2 (SARS-CoV-2). This current viral pandemic started from Wuhan, China, in December 2019 and has spread exponentially to the rest of the world [1]. This is the third novel coronavirus in last 17 years and phylogenetically it is closely related to bat-derived SARS like coronaviruses [2].

SARS-CoV-2 virus utilizes spiny protein $\mathrm{S} 1$, which is responsible for making the virion adhere to cell membrane and the host ACE2 receptor [3]. ACE2 is a functional receptor for SARS-CoV-2, and its nervous system expression and distribution indicates that SARSCoV-2 can induce neurological manifestations via direct or indirect pathways [4]. Because of the unusual morphology of the olfactory system, including the olfactory bulb and the olfactory nerve, viruses may also contribute through the cribriform plate to central nervous system infections [5, 6].

As of August 16, 2020, there were 21,294,845 confirmed cases of COVID-19 and 761,779 deaths globally [7]. COVID-19 has been reported to spread among humans 
across multiple sources, such as droplets, aerosols, feces and oral mucous membranes [8].

In light of the increasing number of true positives and the paucity of test kits and facilities, particularly in developing countries, it is of paramount importance to gauge the number of diagnostic symptoms of this disease in order to make a decision on self-isolation and to prevent infection transmission.

Many studies have documented common clinical symptoms of COVID-19 including fever, cough, diarrhea and fatigue [1]. In comparison, some patients may experience upper respiratory symptoms such as pharyngodynia, sore throat, nasal obstruction, rhinorrhea and alterations in olfaction [9, 10]. Viral pneumonia leading to acute respiratory distress syndrome (ARDS) and even death has been observed in more severe cases [10].

There is steadily growing observational evidence that olfactory disorders are prevalent symptoms in COVID-19 patients, in absence of rhinorrhea and nasal obstruction and can be presenting symptoms before the appearance of other symptoms such as cough and fever. Related studies come from various countries worldwide [11]. Although post viral olfactory dysfunction is common observation in ENT practice and viruses like rhinovirus, parainfluenza, EpsteinBarr virus and some coronavirus have been implicated to cause this via an inflammatory reaction of the nasal mucosa and the development of rhinorrhea, but the olfactory dysfunction that is observed in COVID-19 is usually not associated with rhinorrhea [12, 13].

The role of an otolaryngologist in COVID-19 pandemic is very crucial and, in many, otolaryngologist will be the first to evaluate COVID-19 positive patients. Since SARSCoV-2 is most likely to be transmitted by contact and respiratory droplets (aerosols) [14], ENT examination is a high risk procedure to the healthcare provider over short distances $(1.5 \mathrm{~m})$.

Recent studies have shown that olfaction also affects the quality of life (QOL) [15-18] and olfactory impairment can lead to problems in diverse elements of QOL such as safety, hygiene, and nutrition. Since there have been a rapidly growing number of reports of a significant increase in the number of patients presenting with olfactory dysfunction in the absence of other symptoms, a comprehensive epidemiological review is the need of the hour to characterize olfactory disorders in infected patients.

The aim of this study is to describe the prevalence and characteristics of olfactory dysfunction (OD) in patients with laboratory-confirmed COVID-19 infection and this study is conducted to help the international community in better understanding this novel infectious disease.

\section{Materials and Methods}

This monocentric cross-sectional observational study was conducted at Chest Diseases hospital, an associated hospital of GMC Srinagar, J\&K for duration of five month from April 2020 to august 2020. This is a designated hospital assigned by the Government of India to treat patients with COVID-19. This study is focused on admitted hospital patients that have been identified as having laboratory-confirmed 2019-nCoV infection. The study was reviewed and approved by the Ethical committee of our institution.

All COVID-19 positive patients were isolated with airborne and contact precautions in the designated hospital and attending staff wore personal protective equipment in accordance with the US Centers for Disease Control and Prevention guidelines [19]. Our study focused primarily on patients with mild to moderate COVID-19, described as patients without the need for intensive care. A written informed consent was obtained from all the patients enrolled in this study.

\section{Inclusion Criteria}

1. Individuals confirmed to have COVID-19 by SARSCoV-2 real-time reverse transcriptase-polymerase chain reaction (RT-PCR).

2. Adult ( $>18$ years).

3. Patients clinically stable and having mild to moderate symptoms and able to complete the questionnaire.

\section{Exclusion Criteria}

1. Suspected COVID-19 cases but not laboratoryconfirmed.

2. Patients with history of olfactory dysfunctions before the study.

3. Patients with previous history of head trauma, acute or chronic rhinosinusitis, allergic rhinitis, dementia, malignancy or abnormal nasal anatomy.

4. Patients who are sick and admitted in the intensive care unit at the time of the study.

During our study period, 963 COVID-19 patients were tested positive, out of which 655 were enrolled in this study. The study was performed in accordance with the principles of the Declaration of Helsinki.

Diagnosis was confirmed by real-time PCR (RT-PCR) on nasopharyngeal and oropharyngeal swabs which were placed into a collection tube containing preservation solution for the virus. 
Radiologic assessments included chest and head CT and all laboratory testing (a complete blood cell count, blood chemical analysis, coagulation testing, assessment of liver and renal function testing, C-reactive protein, creatine kinase, and lactate dehydrogenase) were performed according to the clinical needs of the patient.

\section{Clinical and Olfactory Assessment}

Clinical data was prospectively collected during the ear, nose, and throat (ENT) consultation in the isolation ward of the designated hospital. The demographic and clinical variables studied included: age, sex, smoking history, comorbidities, olfaction, general and otolaryngological symptoms. All patients were asked to complete olfactory questionnaires based on the short version of the Questionnaire of Olfactory Disorders-Negative Statements (sQOD-NS). The impact of olfactory dysfunction, if present, on the quality of life (QoL) of patients was assessed through this validated sQOD-NS. This is a 7-item patient reported outcome questionnaire and each item is rated on a scale of $0-3$, with higher scores reflecting better olfactoryspecific QoL. The total score ranges from 0 (severe impact on QoL) to 21 (no impact on QoL) [20]. The study wasn't carried out with the intention to check out the association between olfactory and gustatory dysfunctions in COVID19 positive subjects.

\section{Statistical Methods}

Data was entered in a Microsoft Excel spreadsheet and IBM-SPSS statistical software version 22 was used for analyzing the data. Continuous variables were summarized as mean and standard deviation. Chi-Square test was used to compare between categorially variables. IndependentSamples T-test was used for the comparison of the means. Two-tailed $p$-values were reported and a $p$-value $<0.05$ was considered statistically significant.

\section{Results}

The study was completed by a total of 655 patients. The mean age was $32.7 \pm 10.1$ years with a range of $19-85$ years. In our study, $63.20 \%$ patients $(n=414)$ were males and $36.80 \%(n=241)$ were females (Table 1$)$. Hypertension (15.79\%) and hypothyroidism $(10.52 \%)$ were the most frequent comorbidities in patients. Other comorbidities were less frequent (Fig. 1).

The majority of the study subjects had no history of smoking (74.05\%). The prevalence rate of olfactory dysfunction was $18.47 \%$ with contribution of $11.60 \%$ and
Table 1 Gender wise distribution of cases

\begin{tabular}{lll}
\hline Gender & Number & Percentage $(\%)$ \\
\hline Male & 414 & 63.20 \\
Female & 241 & 36.80 \\
Total & 655 & 100 \\
\hline
\end{tabular}

$6.87 \%$ from anosmia and hyposmia respectively (Table 2). There was a statistically significant difference between the 2 patient groups (with and without olfactory dysfunction) with respect to the following variables: sex and smoking history (Tables 3 and 4). The relative effect of olfactory dysfunction on men and smokers was greater as compared to women and non-smokers (significant at $P<0.05$ ).

\section{Clinical Outcomes}

The general symptoms reported by the patients during the course of infection are illustrated in Fig. 2. The most common symptoms were fever $(76 \%)$, dry cough $(60 \%)$, tiredness $(41.7 \%)$, bodyaches $(35 \%)$, headache $(31 \%)$, nausea/vomiting $(22.9 \%)$, diarrhea $(18.76 \%)$ and anorexia (16.6\%). The otolaryngological symptoms most associated with the infection appear in Fig. 3.

The most common otolaryngological symptom observed in COVID-19 positive subjects was headache (41.7\%) and sore throat $(12.5 \%)$. Rest of ENT symptoms were less frequent (Fig. 3).

\section{Olfactory Analysis}

A total of 121 study participants (18.47\%) had olfactory dysfunction consistent with the COVID-19 infection. Of which, 76 patients $(11.60 \%)$ were anosmic, and 45 (6.87\%) were hyposmic. In $14.29 \%$ patient's olfactory dysfunction evolved prior to appearance of general/otolaryngologic symptoms whereas in $54.29 \%$ and $31.42 \%$ cases OD was noted at the same time or after the advent of general/otolaryngologic symptoms respectively. The mean duration of OD was 7.7 days $( \pm 4.3)$, and $>90 \%$ patients in our study showed resolution within 14 days. The result of olfactory dysfunction on patient QOL is reported in Table 5. Anosmic patients had significantly reduced sQOD-NS results as compared to hyposmic patients (significant at $P<0.05$ ). 


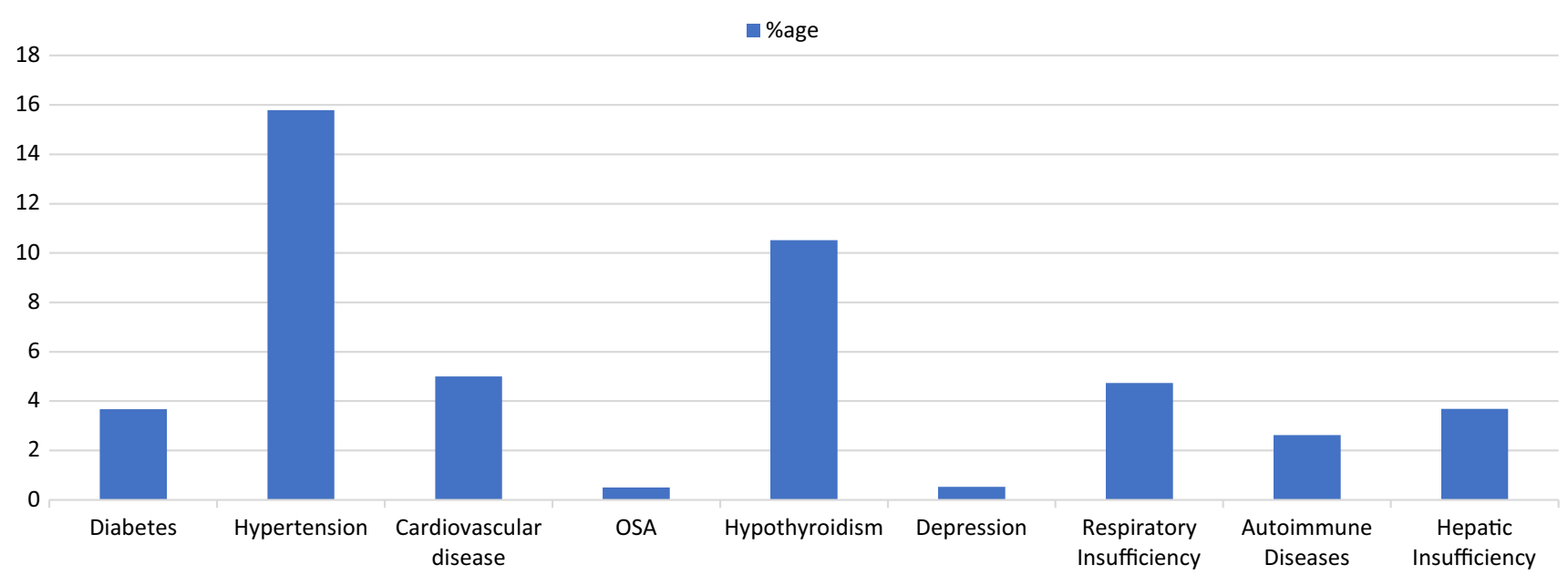

Fig. 1 Comorbidities associated with COVID-19 positive cases

Table 2 Distribution of cases with COVID-19 disease

\begin{tabular}{llll}
\hline Covid-19 cases & Number & $\begin{array}{l}\text { Percentage } \\
(\%)\end{array}$ \\
\hline $\begin{array}{l}\text { Positive cases with olfactory } \\
\text { dysfunction (OD) }\end{array}$ & Anosmia & 76 & 11.60 \\
& Hyposmia & 45 & 6.87 \\
& Total & 121 & 18.47 \\
$\begin{array}{l}\text { Positive cases without olfactory dysfunction } \\
\quad \text { (OD) }\end{array}$ & 534 & 81.53 \\
Total & & \\
\hline
\end{tabular}

\section{Discussion}

Olfactory dysfunction (OD) as an indicator of COVID-19 infection has been reported by many studies since the onset of this pandemic. In recent months, a significant number of otolaryngologists have documented the concurrent symptoms of a sudden anosmia or hyposmia in COVID-19 positive cases. When working with OPD patients, otolaryngologists need to be diligent so that diagnosis of COVID 19 is not delayed and serious attention should be paid to inquiring about the loss of sense of smell in any suspected COVID-19 patient as coronaviruses have historically been associated with encephalitis and chronic

Table 3 Relationship between gender and olfactory dysfunction in COVID-19 cases

\begin{tabular}{|c|c|c|c|c|c|c|c|}
\hline \multirow[t]{2}{*}{ Gender } & \multicolumn{2}{|c|}{ With olfactory dysfunction } & \multicolumn{2}{|c|}{ Without olfactory dysfunction } & \multicolumn{2}{|c|}{ Total } & \multirow[t]{2}{*}{$p$-value } \\
\hline & No. & Age $(\%)$ & No. & Age $(\%)$ & No. & Age $(\%)$ & \\
\hline Males & 86 & 20.77 & 328 & 79.22 & 414 & 63.20 & $<0.05$ \\
\hline Females & 35 & 14.52 & 206 & 85.48 & 241 & 36.80 & \\
\hline Total & 121 & 18.47 & 534 & 81.53 & 655 & 100 & \\
\hline
\end{tabular}

Table 4 Relationship between smoking and olfactory dysfunction in COVID-19 cases

\begin{tabular}{|c|c|c|c|c|c|c|c|}
\hline \multirow[t]{2}{*}{ Smoker } & \multicolumn{2}{|c|}{ With olfactory dysfunction } & \multicolumn{2}{|c|}{ Without olfactory dysfunction } & \multicolumn{2}{|c|}{ Total } & \multirow[t]{2}{*}{$p$-value } \\
\hline & No. & Age $(\%)$ & No. & Age $(\%)$ & No. & Age $(\%)$ & \\
\hline Yes & 97 & 57.05 & 73 & 42.95 & 170 & 25.95 & $<0.05$ \\
\hline No & 24 & 4.95 & 461 & 95.05 & 485 & 74.05 & \\
\hline Total & 121 & 18.47 & 534 & 81.53 & 655 & 100 & \\
\hline
\end{tabular}




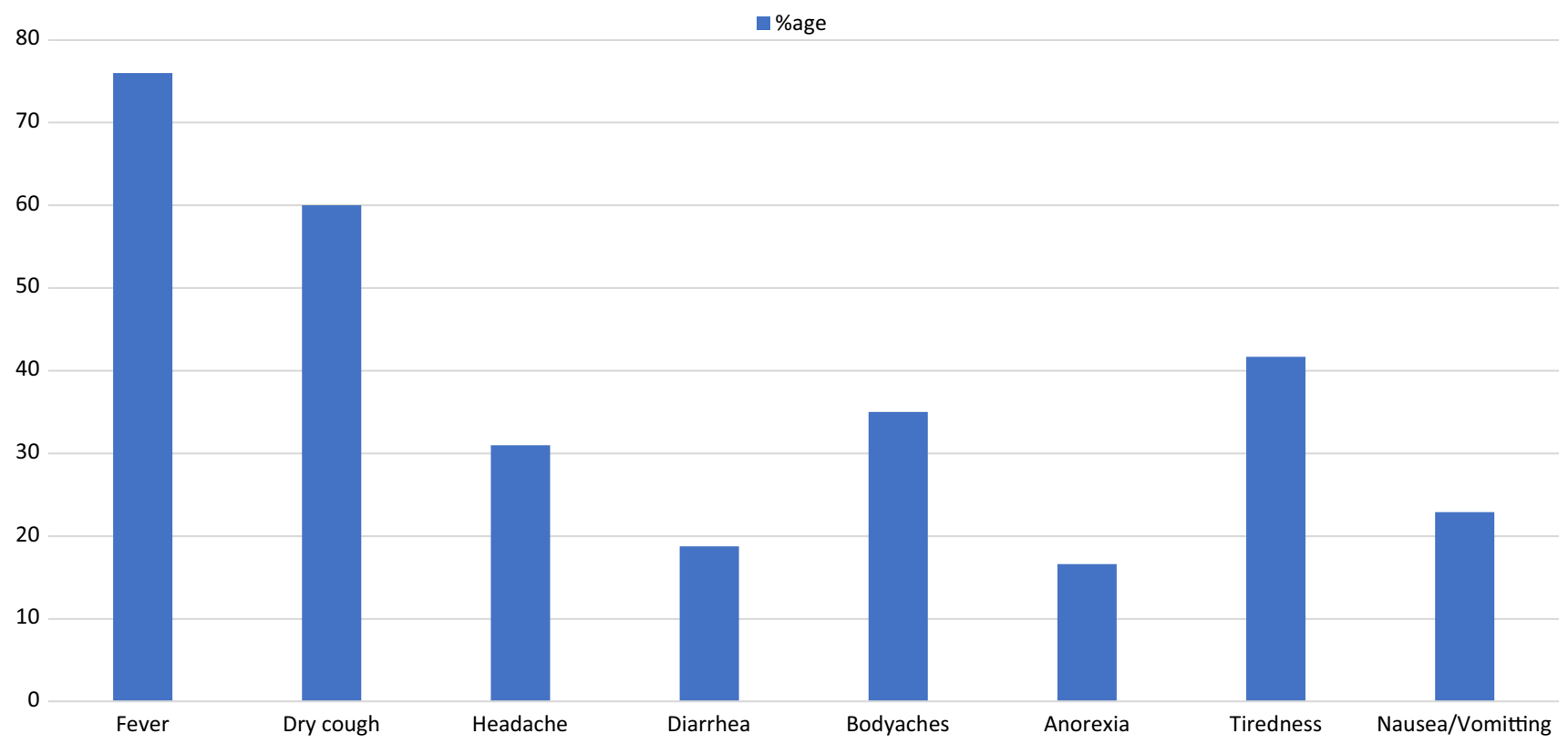

Fig. 2 General symptoms associated with COVID-19 infection

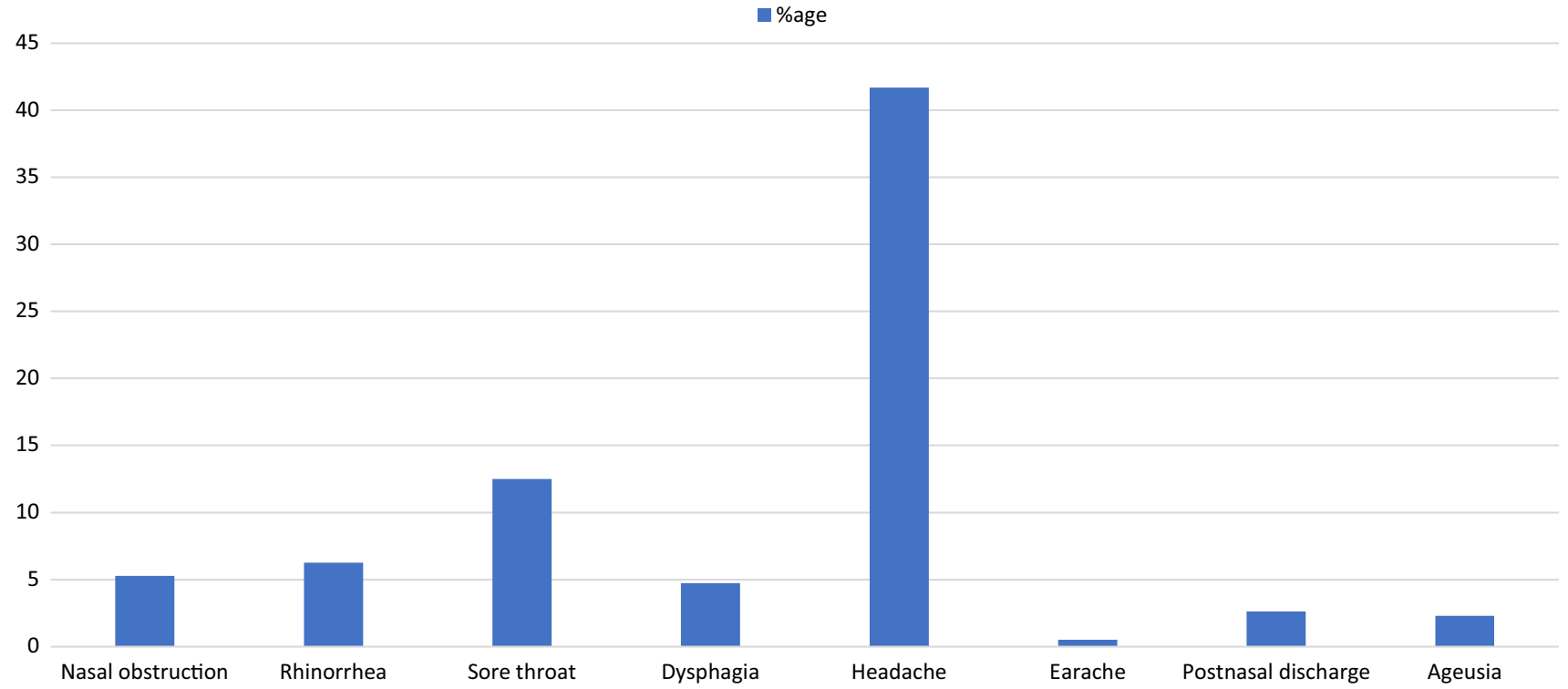

Fig. 3 Otolaryngological symptoms associated with COVID-19 infection

demyelination [21]. Moreover, patients presenting with anosmia during COVID-19 pandemic should be ruled out for this viral disease.

The mean age of our population was $32.7( \pm 10.1)$ years, and $63.20 \%$ were males. Patients with olfactory dysfunction $(n=121)$ seemed to be younger with a predominance of males and had fewer comorbidities. This finding was in contrast to the studies conducted earlier [22-28]. Males have greater predisposition to olfactory dysfunction because they have the higher likelihood of exposure to harmful agents. In addition, estrogen and progesterone might have favorable impacts in peripheral or central olfactory region stem cells, that could delay olfactory decline in women [29, 30]. Moreover, neural function has propensity to diminish more rapidly in men as compared to women [31, 32]. There is a need for future research to analyze the possible gender disparities in the 
Table 5 Short version of Questionnaire of Olfactory Disorders-Negative Statements of patient (sQOD-NS)

\begin{tabular}{|c|c|c|}
\hline Short version QOD-NS items & Anosmia & Hyposmia \\
\hline The changes in my sense of smell make me feel isolated. & $1.81 \pm 0.64$ & $2.76 \pm 0.42$ \\
\hline Because of the changes in my sense of smell, I have problems with taking part in activities of daily life & $1.40 \pm 0.65$ & $2.38 \pm 0.62$ \\
\hline The changes in my sense of smell make me feel angry & $1.63 \pm 0.64$ & $2.38 \pm 0.48$ \\
\hline Because of the changes in my sense of smell, I go to restaurants less often than I used to. & $1.90 \pm 0.84$ & $2.23 \pm 0.69$ \\
\hline Because of the problems with my sense of smell, I eat less than before (loss of appetite) & $2.27 \pm 0.44$ & $2.46 \pm 0.49$ \\
\hline Because of the changes in my sense of smell, I try harder to relax. & $1.59 \pm 0.57$ & $2.23 \pm 0.79$ \\
\hline I am worried that I will never get used to the changes in my sense of smell. & $2.31 \pm 0.46$ & $2.38 \pm 0.48$ \\
\hline Short version QOD-NS total score & $12.95 \pm 2.01$ & $16.84 \pm 2.31$ \\
\hline
\end{tabular}

development of olfactory dysfunction in COVID-19 positive patients.

The correlation between smoking and olfaction may be the consequence of the pro-inflammatory effect on the olfactory epithelium of the chemicals found in cigarette smoke [33]. Olfactory dysfunction has also been attributed to the effects of smoking on vascular system and brain [34]. Our research found low smoker prevalence $(25.95 \%)$ in the study population. This finding was similar to study done by Speth et al. [24], who found a prevalence of $8.8 \%$. However, in our study a statistically significant association was found between smoking and anosmia/hyposmia (significant at $P<0.05)$. The adverse effects of smoking on clinical outcome of COVID-19 patients has also been demonstrated by Kaye et al. [35].

In this study, 655 COVID-19 patients were examined for olfactory dysfunction, out of which 76 patients $(11.60 \%)$ had anosmic symptoms and 45 subjects (6.87\%) had hyposmia. In the present study, the prevalence of olfactory dysfunction was $18.47 \%$ in COVID-19 patients. Compared to Klopfenstein's study the prevalence is lower as $47 \%$ of their patients reported anosmia [36]. Anosmia was also reported by Lechien et al. [22] in up to $86 \%$ of their patients and Paderno et al. [25] documented OD in $83 \%$ of their patients. Tong et al. in a meta-analysis review reported that the prevalence rate of the 10 investigations studying olfactory dysfunction in COVID-19 patients was $52.73 \%$ [37]. These impairments have been more frequently reported in European studies [24]. Nonetheless, the lower prevalence of olfactory dysfunction in our study population is consistent with findings from other Asian studies. Although only few studies on the prevalence of olfactory dysfunctions in Asia have been published so far, one of these studies by Mao et al. documented hyposmia in $5.1 \%$ of subjects [3]. Raid et al. reported that the prevalence rate of olfactory dysfunction was $24.82 \%$ [38] and Prasun et al. showed that the olfactory dysfunctions were seen in $14.8 \%$ of Indian patients [39].
The possible mechanism of difference in prevalence of olfactory dysfunction between European and Asian populations remains to be investigated at the moment, and many potential mechanisms have been hypothesized. First, the virus surface protein mutation, spike $S$ protein, and nucleocapsid $\mathrm{N}$ protein, providing the virus with stability to prevent its entrance into the cell [40]. Second, genetic differences between ethnic groups and their role in viruses affecting particular systems. Third, SARS-CoV-2 affinity for tissues and potential human genetic characteristics [22]. Finally, difference in the degree of expression of ACE2 in various tissues which can affect the sensitivity and outcomes of COVID-19 infection [41]. Hence, even though prevalence of OD in our study sample is lower than that of European subjects, OD in COVID-19 cases does form a significant clinical feature.

Our patients had similar general symptoms as those documented in other studies [1, 8, 42-44], with fever and dry cough being the most common symptoms in our study population. Furthermore, we found that diarrhea was documented in less than $20 \%$ of patients, as was reported in study by Li X et al. [45].

In our study population, otolaryngological symptoms other than OD were particularly less prevalent compared to European cohorts. These findings are similar to study done by Chen et al. who reported rhinorrhea in $4 \%$ patients [44] and Guan et al. who reported nasal obstruction in $5 \%$ of its study subjects [1]. It is critical to discuss such differences between Asians and Europeans cohorts in future studies.

Post viral olfactory loss (POL) can be caused by various kinds of viruses like coronaviruses such as HCoV-229E [11]. In our study the mean duration of OD was 7.7 days $( \pm 4.3)$, and $>90 \%$ patients showed resolution within 14 days. These findings showing a fast recovery time are consistent with the studies by Kaye et al. [35] and Raid et al. [38]. In our study, the median onset of olfactory dysfunction was 3 days after infection onset.

Our study design included a questionnaire for evaluating olfaction-specific QOL in COVID-19 patients with 
olfactory dysfunction, and we used the short version of sQOD-NS for this purpose [20]. Anosmic patients had a substantially lower sQOD-NS score relative to hyposmic subjects (significant at $P<0.05$ ) at the time of assessment. These findings correlated with the study of Lechien et al. [22].

There are various limitations to the present study. First, subjective olfaction tests such as the UPSIT and Sniffin Sticks tests were not employed in this study because of the contagious potential of this infection and to preserve the safety protocols established in our institution and we recommend a further research to use an objective evaluation of these olfactory variations. Second, our subset of patients consisted of mild to moderate COVID-19 patients with little comorbidity and they may not be indicative of the infected communities.

Having said that, our study is the main monocentric cohort of confirmed COVID-19 cases in Jammu and Kashmir and this study is the first to evaluate the prevalence of olfactory dysfunction in COVID-19 positive subjects in this region and the above mentioned limitations need to be considered in future studies for evaluating and characterizing olfactory functions in COVID-19 patients, as any addition to our insight will help us clinicians in early diagnosis and treatment of this disorder.

\section{Conclusion}

Olfactory Impairment's significantly influence daily activities. The early recognition of olfactory dysfunction should help to screen, identify and thereby quickly isolate mildly symptomatic COVID-19 patients from the general population and the existence of these dysfunctions may well be a prognostic factor in the course of the disease. Current epidemiological evidence shows a relatively high prevalence of olfactory dysfunction in a wide range of populations. Therefore, we recommend that the international scientific community must consider new onset anosmia/ hyposmia as significant symptoms of the COVID-19 infection and that primary physicians and otolaryngologists need to be vigilant of this ostensible presentation. This research provides evidence for using olfactory dysfunction as a symptom for increased screening of COVID-19 infections in an attempt to minimize the risk of disease transmission.

\section{Conflict of interest None declared.}

Ethical Approval The study was approved by the Institutional Ethics Committee.

Funding No funding sources.

\section{Bibliography}

1. Guan WJ, Ni ZY, Hu Y et al (2020) Clinical characteristics of coronavirus disease 2019 in China. N Engl J Med 382(18):1708-1720. https://doi.org/10.1056/NEJMoa2002032

2. Lu R, Zhao X, Li J et al (2020) Genomic characterisation and epidemiology of 2019 novel coronavirus: implications for virus origins and receptor binding. Lancet 395(10224):565-574. https://doi.org/10.1016/S0140-6736(20)30251-8

3. Mao L, Jin H, Wang M et al (2020) Neurologic manifestations of hospitalized patients with coronavirus disease 2019 in Wuhan, China. JAMA Neurol 77(6):683-690. https://doi.org/10.1001/jamaneurol.2020.1127

4. Baig AM, Khaleeq A, Ali U, Syeda H (2020) Evidence of the COVID-19 virus targeting the CNS: tissue distribution, host-virus interaction, and proposed neurotropic mechanisms. ACS Chem Neurosci 11(7):995-998. https://doi.org/10.1021/acschemneuro.0c00122

5. Koyuncu OO, Hogue IB, Enquist LW (2013) Virus infections in the nervous system. Cell Host Microbe 13(4):379-393. https://doi.org/10.1016/j.chom.2013.03.010

6. Baig AM (2020) Neurological manifestations in COVID-19 caused by SARS-CoV-2. CNS Neurosci Ther 26(5):499-501. https://doi.org/10.1111/cns.13372

https://www.who.int/docs/default-source/coronaviruse/situationreports/20200816-covid-19-sitrep-209.pdf?sfvrsn=5dde1ca2_2

8. Huang C, Wang Y, Li X et al (2020) Clinical features of patients infected with 2019 novel coronavirus in Wuhan, China [published correction appears in Lancet. 2020 Jan 30]. Lancet 395(10223):497-506. https://doi.org/10.1016/S0140-6736(20)30183-5

9. Lovato A, de Filippis C, Marioni G (2020) Upper airway symptoms in coronavirus disease 2019 (COVID-19). Am J Otolaryngol 41(3): 102474 https://doi.org/10.1016/j.amjoto.2020.102474

10. Lovato A, de Filippis C (2020) Clinical presentation of COVID19: a systematic review focusing on upper airway symptoms [published online ahead of print, 2020 Apr 13]. Ear Nose Throat J:145561320920762. https://doi.org/10.1177/0145561320920762

11. Suzuki M, Saito K, Min WP et al (2007) Identification of viruses in patients with postviral olfactory dysfunction. Laryngoscope 117(2):272-277. https://doi.org/10.1097/01.mlg.0000249922.37381.1e

12. van Riel D, Verdijk R, Kuiken T (2015) The olfactory nerve: a shortcut for influenza and other viral diseases into the central nervous system. J Pathol 235(2):277-287. https://doi.org/10.1002/path.4461

13. Nordin S, Brämerson A (2008) Complaints of olfactory disorders: epidemiology, assessment and clinical implications. Curr Opin Allergy Clin Immunol 8(1):10-15. https://doi.org/10.1097/ACI.0b013e3282f3f473

14. Trilla A (2020) One world, one health: the novel coronavirus COVID-19 epidemic. Un mundo, una salud: la epidemia por el nuevo coronavirus COVID-19. Med Clin (Barc) 154(5):175-177. https://doi.org/10.1016/j.medcli.2020.02.002

15. Keller A, Malaspina D (2013) Hidden consequences of olfactory dysfunction: a patient report series. BMC Ear Nose Throat Disord 13(1):8. $\quad$ Published $2013 \quad$ Jul 23. https://doi.org/10.1186/1472-6815-13-8

16. Landis BN, Konnerth CG, Hummel T (2004) A study on the frequency of olfactory dysfunction. Laryngoscope 114(10):1764-1769. https://doi.org/10.1097/00005537-200410000-00017 
17. Miwa T, Furukawa M, Tsukatani T, Costanzo RM, DiNardo LJ, Reiter ER (2001) Impact of olfactory impairment on quality of life and disability. Arch Otolaryngol Head Neck Surg 127(5):497-503. https://doi.org/10.1001/archotol.127.5.497

18. Katotomichelakis M, Simopoulos E, Zhang N et al (2013) Olfactory dysfunction and asthma as risk factors for poor quality of life in upper airway diseases. Am J Rhinol Allergy 27(4):293-298. https://doi.org/10.2500/ajra.2013.27.3903

19. CDC (2020) Interim infection prevention and control recommendations for patients with suspected or confirmed coronavirus disease 2019 (COVID-19) in healthcare settings. https://www.cdc.gov/coronavirus/2019-ncov/healthcarefacilities/dialysis.html

20. Mattos JL, Edwards C, Schlosser RJ et al (2019) A brief version of the questionnaire of olfactory disorders in patients with chronic rhinosinusitis. Int Forum Allergy Rhinol 9(10):1144-1150. https://doi.org/10.1002/alr.22392

21. Masters P, Perlman S (2013) Coronaviridae. In: Knipe D, Howley $\mathrm{P}$ (eds) Fields virology, 6th edn. Lippincott Williams \& Wilkins, pp 825-858

22. Lechien JR, Chiesa-Estomba CM, De Siati DR et al (2020) Olfactory and gustatory dysfunctions as a clinical presentation of mild-to-moderate forms of the coronavirus disease (COVID-19): a multicenter European study. Eur Arch Otorhinolaryngol 277(8):2251-2261. https://doi.org/10.1007/s00405-020-059651

23. Qiu C, Cui C, Hautefort C et al (2020) Olfactory and gustatory dysfunction as an early identifier of COVID-19 in adults and children: an international multicenter study [published online ahead of print, 2020 Jun 16]. Otolaryngol Head Neck Surg: 194599820934376 . https://doi.org/10.1177/0194599820934376

24. Speth MM, Singer-Cornelius T, Oberle M, Gengler I, Brockmeier SJ, Sedaghat AR (2020) Olfactory dysfunction and sinonasal symptomatology in COVID-19: prevalence, severity, timing, and associated characteristics. Otolaryngol Head Neck Surg 163(1):114-120. https://doi.org/10.1177/0194599820929185

25. Paderno A, Mattavelli D, Rampinelli V et al (2020) Olfactory and gustatory outcomes in COVID-19: a prospective evaluation in nonhospitalized subjects [published online ahead of print, 2020 Jun 30]. Otolaryngol Head Neck Surg:194599820939538. https://doi.org/10.1177/0194599820939538

26. Chary E, Carsuzaa F, Trijolet JP et al (2020) Prevalence and recovery from olfactory and gustatory dysfunctions in COVID-19 infection: a prospective multicenter study. Am J Rhinol Allergy 34(5):686-693. https://doi.org/10.1177/1945892420930954

27. Vaira LA, Deiana G, Fois AG et al (2020) Objective evaluation of anosmia and ageusia in COVID-19 patients: single-center experience on 72 cases. Head Neck 42(6):1252-1258. https://doi.org/10.1002/hed.26204

28. Lee Y, Min P, Lee S, Kim SW (2020) Prevalence and duration of acute loss of smell or taste in COVID-19 patients. J Korean Med Sci 35(18):e174. Published 2020 May 11. https://doi.org/10.3346/jkms.2020.35.e174

29. Pawluski JL, Brummelte S, Barha CK, Crozier TM, Galea LA (2009) Effects of steroid hormones on neurogenesis in the hippocampus of the adult female rodent during the estrous cycle, pregnancy, lactation and aging. Front Neuroendocrinol 30(3):343-357. https://doi.org/10.1016/j.yfrne.2009.03.007

30. Lennington JB, Yang Z, Conover JC (2003) Neural stem cells and the regulation of adult neurogenesis. Reprod Biol Endocrinol 1:99. $\quad$ Published $2003 \quad$ Nov 13. https://doi.org/10.1186/1477-7827-1-99

31. Lipnicki DM, Sachdev PS, Crawford J et al (2013) Risk factors for late-life cognitive decline and variation with age and sex in the Sydney Memory and Ageing Study. PLoS One 8(6):e65841.
Published

2013

Jun

14.

https://doi.org/10.1371/journal.pone.0065841

32. Doty R, Shaman P, Applebaum S, Giberson R, Siksorski L, Rosenberg L (1984) Smell identification ability: changes with age. Science 226(4681):1441-1443. http://www.jstor.org/stable/1693918. Accessed 15 Sep 2020

33. Vent J, Robinson AM, Gentry-Nielsen MJ et al (2004) Pathology of the olfactory epithelium: smoking and ethanol exposure. Laryngoscope https://doi.org/10.1097/00005537-200408000-00012

34. Schubert CR, Cruickshanks KJ, Fischer ME et al (2015) Carotid intima media thickness, atherosclerosis, and 5-year decline in odor identification: the Beaver Dam Offspring Study. J Gerontol A Biol Sci Med Sci 70(7):879-884. https://doi.org/10.1093/gerona/glu158

35. Kaye R, Chang CWD, Kazahaya K, Brereton J, Denneny JC 3rd. (2020) COVID-19 anosmia reporting tool: initial findings. Otolaryngol Head Neck Surg 163(1):132-134 https://doi.org/10.1177/0194599820922992

36. Klopfenstein T, Kadiane-Oussou NJ, Toko L et al (2020) Features of anosmia in COVID-19. Med Mal Infect 50(5):436-439. https://doi.org/10.1016/j.medmal.2020.04.006

37. Tong JY, Wong A, Zhu D, Fastenberg JH, Tham T (2020) The prevalence of olfactory and gustatory dysfunction in COVID-19 patients: a systematic review and meta-analysis. Otolaryngol Head Neck Surg 163(1):3-11. https://doi.org/10.1177/0194599820926473

38. Al-Ani RM, Acharya D (2020) Prevalence of anosmia and ageusia in patients with COVID-19 at a Primary Health Center, Doha, Qatar [published online ahead of print, 2020 Aug 19]. Indian J Otolaryngol Head Neck Surg:1-7. https://doi.org/10.1007/s12070-020-02064-9

39. Mishra P, Gowda V, Dixit S, Kaushik M (2020) Prevalence of new onset anosmia in COVID-19 patients: is the trend different between European and Indian population? [published online ahead of print, $2020 \mathrm{Jul} 21$ ]. Indian J Otolaryngol Head Neck Surg:1-4. https://doi.org/10.1007/s12070-020-019868

40. Benvenuto D, Giovanetti M, Ciccozzi A, Spoto S, Angeletti S, Ciccozzi M (2020) The 2019-new coronavirus epidemic: evidence for virus evolution. J Med Virol 92(4):455-459. https://doi.org/10.1002/jmv.25688

41. Li W, Zhang C, Sui J et al (2005) Receptor and viral determinants of SARS-coronavirus adaptation to human ACE2. EMBO J 24(8):1634-1643. https://doi.org/10.1038/sj.emboj.7600640

42. Wang Z, Yang B, Li Q, Wen L, Zhang R (2020) Clinical features of 69 cases with coronavirus disease 2019 in Wuhan, China. Clin Infect Dis 71(15):769-777. https://doi.org/10.1093/cid/ciaa272

43. Wu J, Liu J, Zhao X, Liu C, Wang W, Wang D, Xu W, Zhang C, Yu J, Jiang B, Cao H, Li L (2020) Clinical characteristics of imported cases of coronavirus disease 2019 (COVID-19) in Jiangsu Province: a multicenter descriptive study. Clin Infect Dis 71(15):706-712. https://doi.org/10.1093/cid/ciaa199

44. Chen N, Zhou M, Dong X et al (2020) Epidemiological and clinical characteristics of 99 cases of 2019 novel coronavirus pneumonia in Wuhan, China: a descriptive study. Lancet 395(10223):507-513. https://doi.org/10.1016/S0140-6736(20)30211-7

45. Li X, Geng M, Peng Y, Meng L, Lu S (2020) Molecular immune pathogenesis and diagnosis of COVID-19. J Pharm Anal 10(2):102-108. https://doi.org/10.1016/j.jpha.2020.03.001

Publisher's Note Springer Nature remains neutral with regard to jurisdictional claims in published maps and institutional affiliations. 